\title{
MAKNA ZIKIR BAGI JEMAAH \\ TAREKAT NAQSHABANDĪYAH KHĀLĪDĪYAH MAJELIS PENGKAJIAN TAUHID TASAWUF INDONESIA DI KOTA GORONTALO
}

\author{
Rahmawati \\ Institut Agama Islam Negeri Sultan Amai Gorontalo, Indonesia \\ E-mail: rahmatjatjo@iaingorontalo.ac.id \\ Kasim Yahiji \\ Institut Agama Islam Negeri Sultan Amai Gorontalo, Indonesia \\ E-mail: kasimyahiji@iaingorontalo.ac.id \\ Mustakimah \\ Institut Agama Islam Negeri Sultan Amai Gorontalo, Indonesia \\ E-mail: mustakimah@iaingorontalo.ac.id
}

\begin{abstract}
This article attempts to elaborate the existence of dhikr along with its meaning performed and hold by the members of the Majelis Pengkajian Taubid Tasawnf Indonesia under the auspices of the Tarekat Naqshabandiyah Khālidīyah in Gorontalo City. The study indicates that dhikr is a substantially mandatory ritual that must be performed by the followers of the tarekat. In this point they interpret the meaning of dhikr within various arguments. The tarekat members who reached what so-called the level of tawhid 'aqidah argue that dhikr is an important matter which brings about positive energy and leads its performers to discover true religious spirituality. They believe that the positive energy becomes significantly determinant factor and it has relevance to solve the problems of daily life. On the other side, the tarekat members who have reached the level of tawhid süfi interpret dhikr as a spiritual obligation which orients its performers to lovingness and intimacy with God. To the urban society of Gorontalo dhikr is viewed as a mindset which emphasizes that within spiritually sacred realm, on one hand, dhikr provides a positive indication which is coherently compatible with the profane reality of their life on the other.
\end{abstract}

Keywords: Majelis Pengkajian Taubid Tasawnf Indonesia; the Tarekat Naqshabandīyah Khālidīyah; dhikr. 


\section{Pendahuluan}

Dalam beberapa dekade terakhir ini, banyak peneliti yang menggeluti secara intensif studi tentang tarekat. Beberapa penelitian yang mengupas tentang tarekat antara lain disusun kertas kerjanya oleh Misbahul Munir, ${ }^{1}$ Martin Van Bruinessen, ${ }^{2}$ Nursyam, ${ }^{3}$ Gazali Rahman, ${ }^{4}$ Ahmad Khoirul Fata ${ }^{5}$ dan beberapa kertas kerja lain. Sebagian penelitian berupaya mengkaji tarekat dari perspektif sosiologis, historis dan tidak sedikit yang mengaitkannya dengan disiplin keilmuan lain. Dari aspek genealogi ilmu, tarekat tidak lain lahir dari tasawuf, ilmu yang mengelaborasi tentang cara pendekatan diri kepada Allah. Disiplin ini lahir dari rahim sejarah umat Islam yang tidak lepas dari pro kontar dan ketegangan. ${ }^{6}$

Kemunculan tasawuf telah memicu polemik intelektual di kalangan sarjana Muslim. Sebagian menerima dan sebagian lainnya menolak. Bagi pendukungnya, tasawuf dan tarekat masih merupakan induksi dari ajaran Islam murni yaitu iḥsān. Sementara bagi penolaknya yang mayoritas adalah ulama hadīth, kelompok puritanis-literalis dan sebagian orientalis menyebut bahwa tasawuf dan tarekat telah mengalami percampuran dengan mistisisme dari luar Islam, bahkan dikatakan sebagai heterodoksi. Meskipun kelahiran dan eksistensinya tidak lepas dari polemik, tasawuf dan aspek particular di dalamnya hingga kini tetap saja menjadi suatu disiplin ilmu keislaman yang menarik untuk dikaji. Lebih-lebih ketika tasawuf diyakini turut andil dalam penguatan kehidupan spiritual, sosial, dan politik pada masyarakat Muslim.

Berdasarkan sumber historis, tasawuf merupakan bentuk kritik sosial terhadap kondisi politik umat yang tidak adil atau melenceng dari tuntunan Rasulullah. Seperti apa yang dilakukan Abū Dhar, yang diyakini sebagi sufi pertama ketika memilih kehidupan zuhud untuk mengkritik penguasa dan aristokrat waktu itu yang bermewah-mewah, sementara tidak memperdulikan nasib rakyat jelata. Pun demikian

\footnotetext{
1 Misbahul Munir, "Rasionalisasi Gerakan Kewirausahaan Organisasi Tarekat Șiddîqîyah di Jombang", Islamica: Jurnal Studi Keislaman, Vol. 9, No. 2 (2015).

2 Martin van Bruinessen, Kitab Kuning, Pesantren, dan Tarekat, terj. Farid Wajidi (Yogyakarta: Gading Publishing, 2015).

${ }^{3}$ Nursyam, Pembangkangan Kaum Tarekat (Surabaya: LEPKISS, 2004).

4 Gazali Rahman, "Kontroversi Pemahaman dan Pengamalan Syariat Majelis Zikir Ya Allahu di Kota Gorontalo," al-Qalam, Vol. 23. No. 1 (2017).

5 Ahmad Khoirul Fata, "Tarekat," al-Ulum, Vol. 11, No. 2 (2011), 373-384.

${ }^{6}$ Bruinessen, Kitab Kuning, 198.
} 
dengan Ḥasan al-Bașrī (W. 110 H/728 M) yang menyayangkan gaya hidup sebagian besar umat Muslim yang lebih mementingkan urusan duniawi dari pada ukhrawi, sehingga tidak mengindahkan lagi perkara halal dan haram. Sebagai reaksi atas perubahan gaya hidup kaum Muslim itu, maka ia berkata: "Dulu kami menjumpai beberapa kaum yang mana terhadap perkara halal saja mereka lebih zuhud dari pada kehati-hatian kalian terhadap perkara haram". Sejalan dengan Abū Dhar dan Hasan al-Bașrī, Abū Ḥāmid al-Ghazālī pun melontarkan kritik tajam kepada penguasa di negerinya dengan mengirimkan suratsurat protes atas perilaku mereka yang dinilai tidak baik dan melenceng dari garis yang diteladankan Rasulullah. Begitu pula dengan Said Nursi, seorang sufi besar Turki abad kedua puluh yang melawan pemerintah sekuler Mustafa Kemal Ataturk dan mengkritik keras paham materialisme yang dianut oleh pemerintah Turki melalui sebuah tulisan berjudul Risalah-i Nur. Hingga pengaruh tulisan itu menyebar ke lebih dari 40 negara. ${ }^{7}$

Di Indonesia sendiri, sekitar abad ke-13 dan $14 \mathrm{M}$, peran kaum sufi tidak bisa dinafikan dalam proses islamisasi waktu itu. ${ }^{8}$ Fakta historis ini didukung oleh tesis A.H. John yang menyebut proses islamisasi awal di Nusantara bersamaan waktunya dengan penguatan dominasi sufisme di dunia Islam pasca Bagdad jatuh di tangan Mongol tahun $1258 \mathrm{M}$. Pada era itulah kaum sufi dari pelbagai bangsa datang ke Nusantara untuk menyebarkan agama Islam kepada Raja dan penguasa. ${ }^{9}$ Dalam proses islamisasi ini kaum sufi menerapkan pendekatan sufistik yang damai, ramah dan toleran $^{10}$ sehingga nyaris proses konversi agama lama ke Islam di Nusantara terjadi tanpa perang. Salah satu faktor penyebab kesuksesan dakwah melalui pendekatan sufistik ialah penekanan pada wilayah esoteris agama dari pada wilayah eksoterisnya.

Penekanan pada wilayah esoteris Islam itulah yang melatarbelakangi kelahiran tasawuf. Menurut pandangan kaum sufi, pola pendekatan diri (taqarrub) kepada Allah secara eksoteris tidaklah cukup. Untuk itu perlu pendekatan esoteris sehingga terjadi sinergi antara kehidupan duniawi dan kehidupan ukhrawi. Dari perspektif ini

${ }^{7}$ Lihat Said Nursi, Sinar yang Mengungkap Sang Cahaya, terj. Hariyanto dkk (Jakarta: Murai Kencana, 2003), 42.

8 Azyumardi Azra, Jaringan Ulama Timur Tengah dan Kepulauan Nusantara Abad XVIIXVIII (Jakarta: Kencana, 2010), 15.

${ }^{9}$ Ibid., 15-16.

${ }^{10}$ Azyumardi Azra, Renaisans Islam Asia Tenggara (Bandung: Rosda Karya, 2012), xv. 
kemudian muncullah pelaku tasawuf yang melakukan kegiatan kontemplasi secara individual maupun kolektif. Di antara tokoh sufi yang dikenal tanpa terikat oleh sebuah institusi sufi seperti Rābi'ah al'Adawìyah, Ḥasan al-Bașrị, dan Dhū Nūn al-Mișrī. Selain sufi yang menempuh jalan tasawuf secara individual, ada juga sufi yang menempuhya secara kolektif. Mereka ini tokoh-tokoh sufi pendiri tarekat yang sudah menerapkan suatu sistem pengajaran dan praktik tasawuf (riyadah) yang lebih terorganisir dan sistematis untuk diajarkan kepada murid-murid mereka. Dalam perkembangannya kini, kelompok sufi tarekat lebih dominan pengaruhnya di tengah masyarakat Muslim dibanding dengan kelompok sufi pertama. Hal ini disebabkan proses transmisi ( (jająah) sanad dan ajaran sufi yang terjaga di dalam tarekat.

Seiring waktu, tarekat mengalami perkembangan yang sangat pesat. Salah satu buktinya hingga saat ini banyak nama tarekat yang dikenal oleh masyarakat Muslim. Di antara nama-nama tarekat ada yang tergolong muktabarah dan sebagian kecil tergolong tidak muktabarah. Satu dari tarekat muktabarah itu adalah tarekat Naqshabandīyah yang berkembang di beberapa negara dan memiliki pengikut yang cukup besar. Tarekat ini didirikan oleh Shaykh Muhammad b. Muhammad Bahā' al-Dīn al-'Uwaysī al-Bukhārī alNaqshabandī (1390 M). Silsilah tarekat ini menyambung kepada Abù Bakr al-Ṣiddīq, yang kemudian secara turun-temurun ditansmisikan dari guru ke murid hingga menyebar ke Indonesia termasuk di Sulawesi melalui Yusuf al-Makassari (1623-1699 M). ${ }^{11}$

Penyebaran tarekat Naqshabandīyah di Sulawesi tepatnya di Gorontalo sendiri diperkirakan terjadi sekitar tahun 1979. Ajaran tarekat Naqshabandīyah ini pertama kali dikenalkan oleh Maulana S.S.H. Amiruddin K.Y. b. Moh. Khoir Hasjim al-Kholidy. Seiring waktu tarekat ini semakin berkembang dan dikenal oleh masyarakat Sulawesi seperti di Manado, Bolaang Mongondow, Popayato, Tilamuta, dan bahkan sampai ke Palu Sulawesi Tengah. Tarekat Naqshabandīyah Khālidīyah (TNK) memiliki karakteristik berbeda dibandingkan dengan tarekat-tarekat pada umumnya. Salah satu perbedaannya ada pada ritual zikir yang mana dalam praktiknya seorang murid akan menghadirkan seorang mursid Kämil Mukammil sebagai medium (wasilah) untuk bermunajat kepada Allah. Di

11 Martin Van Huneseen, Tarekat Naqsyabandiyah di Indonesia (Bandung: Mizan, 1992), 99. 
Gorontalo, para penganut TNK menggabungkan diri dalam suatu organisasi bernama Majelis Pengkajian Tauhid Tasawuf Indonesia (MPTTI) yang menjadi subjek dari artikel ini.

Hal menarik yang mendorong penulis menjadikan MPT'TI sebagi subjek adalah ajaran dan praktik tasawuf di dalamnya yang menyeimbangkan antara kebutuhan duniawi dan ukhrawi. Selain itu, MPTTI mengenalkan tarekat kepada masyarakat dengan caranya yang mudah dan ringan sehingga cocok dengan kultur masyarakat modern yang lebih condong ke sesuatu yang praktis. Maka dalam tulisan ini akan diulas salah satu aspek dari TNK MPT'TI yang memiliki posisi penting bagi penganutnya yaitu ritual zikir. Artikel ini akan fokus pada makna zikir bagi jemaah tarekat dan relevansinya dalam kehidupan sehari-hari mereka.

\section{Geneologi dan Ajaran Tarekat Naqshabandīyah Khālidīyah MPTTI}

Nama taraket Naqshabandīyah dinisbatkan kepada nama daerah di mana pendiri tarekat ini berasal. Nama lengkap pendiri tarekat Naqshabandīyah adalah Muhammad b. Muhammad Bahā' al-Dīn al'Uwaysī al-Bukhārī al-Naqshabandī, lahir pada tahun 1318 di Desa Qasr-i Hiduvan (yang kemudian bernama Qasr-i Arifan) di dekat Bukhara. Di tempat yang sama beliau menghembuskan nafas terakhir pada tahun 1389. Beliau menghabiskan sebagian besar hidupnya di Bukhara, Uzbekistan, Transoxiana, dan daerah-daerah di sekitarnya untuk menjalani kehidupan sufi dan mengajarkan tasawuf kepada murid-muridnya yang ada di dekatnya. ${ }^{12}$ Bahā' al-Dīn memiliki silsilah dengan khawajagan, yaitu para guru dalam mata rantai tarekat Naqshabandīyah. Ketika masih bayi, beliau diadopsi sebagai anak spiritual oleh Baba Muhammad Sammasī. Pada usia 18 tahun ia mendalami ilmu tasawuf kepada Amir Sayyid Kulal al-Bukhārī (w. 772/1371). Melalui ijazah dari gurunya inilah beliau kemudian dikenal sebagai penggagas tarekat Naqshabandìyah.

Tarekat Naqshabandīyah adalah salah satu tarekat besar yang silsilah ajarannya bersambung dengan Nabi Muhammad melalui sahabat Abū Bakr al-Ṣiddīq. Umumnya silsilah tarekat bersambung sanadnya melalui sahabat 'Alī b. Abū Țālib sebelum sampai kepada Nabi Muhammad. Asas dan rukun tarekat Naqshabandīyah terbina

12 J. Spencer Trimingham, The Sufi Orders in Islam (London: Oxford University Press, 1973), 85. 
oleh lima bintang yang bersinar di atas jalan Rasulullah yang juga menjadi penciri dari tarekat-tarekat lain. Lima bintang yang dimaksud adalah Abū Bakr al-Ṣiddīq, Salmān al-Fārisī, Abū Yazīd al-Bastāmī, 'Abd al-Khāliq al-Ghujdawan̄i, dan Muhammad Bahā' al-Dīn.

Di antara pengamal tarekat Naqshabandīyah yang berkembang di Indonesia salah satunya berafiliasi ke dalam Tarekat Naqshabandīyah Khālidīyah MPT'TI yang digagas oleh Abuya Shaykh H. Amran Waly al-Khalidi. Ayahnya bernama Abuya Shaykh H. Muhammad Waly alKhalidi, seorang ulama besar di Aceh yang hidup tahun 1917-1961 M juga pendiri Pesantren Darussalam Labuhan Haji Aceh Selatan. Shaykh H. Amran Waly al-Khalidi menimba ilmu dari orang tuanya dan gurunya yaitu Shaykh Zakaria Labai Sati (Sumatera Barat) dan Imam Syamsuddin (Sangkalan Aceh barat Daya). Riwayat pendidikan Shaykh H. Amran antara lain; pernah belajar di Pesantren Riyadhus Shalihin yang diasuh oleh Abu H. Daud Zamzami (Banda Aceh), kemudian melanjutkan pendidikan di perguruan tinggi baik di Aceh maupun di Sumatera Barat, juga pernah belajar di Collage Islam Lampuri, Kotabaru Kelantan Malaysia.

Jabatan yang pernah dilalui antara lain: 1) Pimpinan Pondok Pesantren Darus Salam Labuhan Haji selama 10 tahun (1972-1982); 2) Pimpinan Pondok Pesantren Darul Ihsan Desa Pawoh Labuhan Haji (1982 sampai sekarang); 3) Anggota DPR TK II Kabupaten Aceh Selatan Priode (1982-1987). Pada tahun 2004 beliau mendirikan Majelis Pengkajian Tauhid Tasawuf Indonesia (MPTTI) yang kemudian berkembang seantero Nusantara bersama dengan guru-guru besar tasawuf baik dari Malaysia dan Jawa seperti Shaykh Ibrahim Muhammad dari Malaysia, Shaykh Rahimuddin Nawawi dari Banten, dan DR. M. Dhiyauddin Kuswandi dari Surabaya dan lain-lain. MPTTI sendiri pernah mengadakan tiga kali seminar dan Muzakarah Ulama Tauhid Tasawuf se-Asia Tenggara; pertama di Meulaboh Aceh Barat tahun 2010, dan yang kedua di Selangor Malaysia tahun 2012, yang dihadiri ulama-ulama Asean, serta yang ketiga di Blang Pidie Aceh Barat Daya tahun 2014, yang dihadiri ulama tarekat dari Turki (Shaykh Fāḍil al-Jīlānī (cucu Shaykh 'Abd al-Qādir al-Jaylānī), dan beberapa ulama lainnya.

Shaykh Abuya H. Amran Waly al-Khalidi mendapat izin mengembangkan tarekat Naqshabandīyah oleh tuannya Shaykh 'Aidarus Kampar putra dari Shaykh Abdul Gani al-Kampari. Untuk mengembangkan tarekat ini beliau diberi kitab Majmū'ah Rasā'il yang 
disusun oleh Shaykh Sulaymān Zuhdi sebagai pedoman dalam mengajarkan tarekat Naqshabandīyah Khālidīyah. Tarekat Naqshabandīyah Khālidīyah MPTTI memiliki izin pendirian dengan Surat Keputusan Menteri Hukum dan Hak Asasi Manusia Republik Indonesia nomer AHU-00145. AH.02.01 tahun 2016 tanggal 02 Februari 2016.

Adapun tujuan pendidikan dan dakwah yang hendak dicapai dalam tarekat Naqshabandīyah Khālidīyah MPTTI adalah: Pertama, membimbing dan mendidik manusia untuk mengenal Allah yang wajib disembah melalui pendekatan ibadah, zikir, dan ma'rifah. Kedua, membimbing dan mengarahkan manusia bertaqwa dan berakhlak mulia serta kepedulian sosial untuk kemanusiaan. Ketiga, membimbing manusia untuk selalu bersyukur atas semua limpahan nikmat yang diberikan kepada semua umat manusia. ${ }^{13}$

Tarekat Naqshabandīyah Khālidīyah MPT'TI yang ada di Gorontalo berdiri pada 11 Oktober 2016 yang di pimpin oleh Dr. H. Hamdan Ladiku. Komisariatnya bertempat di Jalan Budi Uutomo Kelurahan Limba Kota Selatan Gorontalo. Pada usianya yang masih sangat muda namun TNK MPT'TI mampu bersaing dengan tarekat lainnya yang ada di Gorontalo. Pengikutnya tarekat ini berasal dari latar belakang sosial yang heterogen; dari akademisi, pengusaha, dan juga generasi muda. Nilai tambah dari TNK MPT'TI sehingga dapat diterima oleh pelbagai kalangan masyarakat karena ajaran spiritualnya yang simpel dan praktis. Selain itu TNK MPT'TI sangat menekankan pengamalan syariat dalam berperilaku bagi pengikutnya dalam menjalani kehidupan bermasyarakat, pun tarekat ini mengedepankan akhlak yang baik dalam keseharian sebagai jalan tasawuf bagi pengikut-pengikutnya.

\section{Makna Zikir dan Urgensinya dalam Tarekat}

Era globalisasi yang penuh dengan kompleksitas persoalan, menuntut manusia agar mencari alternatif penyelesaian. Salah satu persoalan yang tengah dihadapi manusia di era sekarang adalah krisis spiritual. Untuk mengobatinya, manusia kemudian mencari tambatan agar krisis spiritual itu teratasi. Salah satu solusi alternatif ialah menjadikan agama sebagai sebuah kebutuhan dasar (basic need). Maka

13 Lihat Surat Keputusan Menteri Hukum dan Hak Asasi Manusia Republik Indonesia Nomor: AHU- 00145.AH.02.01 tahun 2016, tanggal 02 Februari 2016 tentang Akta Pendirian Perkumpulan Majelis Pengkajian Tauhid Tasawuf Indonesia. 
tak heran apabila saat ini geliat keagamaan sangat dekat dengan kehidupan perkotaan. Kegandrungan masyarakat modern terhadap spiritualitas membuka ruang bagi kemunculan tempat-tempat pemenuhan kebutuhan spiritualitas ini. Ciri dari kelompok ini adalah kecenderungan mereka kepada yang bersifat spiritual dari pada religius konvensional formal yang terorganisir. Mereka tidak tertarik pada ikata-ikatan agama, sebaliknya lebih mengarah kepada kebebasan dan kepuasan dimensi spiritual melalui guru-guru rohani. ${ }^{14}$

Dahaga spiritualitas yang dialami manusia modern disebabkan karena mereka kehilangan visi metafisis. Mereka terlalu asik dengan dimensi materialisme sehingga lupa akan kodrat spiritualisme yang menjadi kebutuhan dasarnya. Maka seiring waktu, mereka pun merasakan kehampaan dari materialisme yang membelenggu kehidupan mereka itu. Pada titik ini manusia modern merasakan kehampaan yang mendera aspek batinnya. Aspek batin inilah yang sudah lama tidak diperhatikan karena mereka dialihkan oleh hasrat duniawi dan melupakan asupan batin melalui zikir, ibadah, dan pencerahan agama. Sains dan teknologi yang mereka banggakan tidak mampu memberikan kepuasan spiritual, pada kondisi seperti inilah jalan kerohanian sangat dibutuhkan.

Dalam Islam, praktik kerohanian dalam kehidupan sehari-hari sejatinya sudah dekat dengan pribadi Muslim melalui aktivitas ibadah yang ditetapkan syariat. Aktivitas ibadah ini merujuk kepada ajaran alQur'ān dan Sunnah. Dalam ibadah sendiri ada dua dimensi di dalamnya yaitu eksoteris dan esoteris. Selain dimensi formal ritual yang masuk domain eksoteris $(f i q h)$, ibadah juga memiliki aspek batin yang masuk domain esoteris (tasawwuf). Misalnya salat, pada ranah eksoteris, ritual salat berarti rangkaian rukun yang dimulai dari niat sampai ditutup dengan salam. Sedangkan pada ranah esoteris salat dimaknai sebagai medium komunikasi seorang Muslim dengan Allah. Maka, secara sederhana dapat dipahami eksoteris berarti aspek lahir, sementara esoteris adalah aspek batin. Tasawuf dalam Islam menjadi puncak pengalaman batin dari integrasi iman, Islam, dan ihsan. Dalam tasawuf cara mencapai puncak pengalaman batin itu dilalui dengan mengelaborasi cara-cara pendekatan diri (murāqabab) kepada Allah

\footnotetext{
${ }^{14}$ Seyyed Hossein Nasr, Islam and The Plight of Modern Man (Bandung: Pustaka, 1991), 14. Nurcholish Madjid, IslamKemodernan dan Keindonesiaan (Bandung: Mizan, 1999), 156. Komaruddin Hidayat, Tragedi Rajan Midas: Moralitas Agama dan Krisis Modernisme (Jakarta: Paramadina, 1998), 277.
} 
melalui zikir dan tawajjuh di bawah bimbingan seorang murshid, inilah yang disebut tarekat.

Kata tarekat berasal dari bahasa Arab tariqah yang mempunyai bentuk plural taräiq dan turuq yang berarti jalan, metode, sistem, mazhab, dan aliran. ${ }^{15}$ Istilah ini membentuk dua makna istilah yaitu: 1 ) Metode bagi ilmu jiwa akhlak yang mengatur praktik sulük individu; dan 2) Kumpulan sistem pelatihan ruh yang berjalan sebagai persahabatan pada kelompok-kelompok persaudaraan Islam". ${ }^{16}$ Sedangkan menurut Martin van Bruinessen, tarekat digunakan dalam dua hal yang secara konseptual berbeda. Makna aslinya adalah "jalan" yang merupakan panduan doktrin, metode, dan ritual yang mempunyai karakteristik tersendiri, namun kemudian definisi ini meluas untuk menamai sebuah institusi yang mengorganisir pengikutpengikut "jalan" tersebut dan inilah yang disebut tarekat. ${ }^{17}$

'Abd al-Mun'im al-Hafnī menjekaskan bahwa tarekat adalah sekumpulan ritual dan peraturan yang disusun oleh pemimpin tarekat (shaykh al-tariqah) agar murid-murid tarekat (muridin) dapat mencapai tujuan yang diinginkan, yakni wusūl kepada Allah. ${ }^{18}$ Sementara menurut Aboebakar Atjeh, tarekat adalah jalan, petunjuk dalam melakukan suatu ibadah sesuai dengan ajaran yang dicontohkan oleh Rasulullah yang dilanjutkan oleh sahabat, täbi ìn, kemudian diwariskan

${ }^{15}$ Lois Ma’luf, al-Munjid al-Lughāh wa A 'làm (Beirut: Dār al-Mashriq, 1975), 465.

16 Muhammad Sabit al-Fandī, dkk., Dāirāàt al-Ma 'ärif al-Islāmīyāh, Vol. 15 (Teheran: Intisyarat Jahham, t.th.), 172.

${ }_{17}$ Martin van Bruinessen, Tarekat Naqsyabandiyah di Indonesia: Survey Historis, Geografis, Sosiologis (Bandung: Mizan, 1996), 61.

18 'Abd al-Mun'im al-Hafnī, al-Mawsū'ah al-Süfíyah (Kairo: Maktabah Madbūīi, 2003), 852. Meskipun bermunculani pelbagai macam tarekat yang berkembang dewasa ini namun tujuannya sama yaitu memperhalus akhlak dan makrifat Allah. Perbedaan antartarekat hanya terletak pada wirid, zikir dan tata cara pelaksanannya. Proses kegiatan tarekat pada umumnya diawali dengan baiat (pengambilan sumpah) di hadapan murshid setelah murid melakukan tobat nasüḥah. Dalam beberapa literatur dijelaskan bahwa tarekat 'Alawìah tidak melakukan bait pada anggotanya. Lihat selengkapnya Alwi Shihab, Akar Tasawuf di Indonesia (Depok: Pustaka IIMaN, 2009), 183-184; mengenai pokok-pokok tarekat 'Alawiyah sebagaimana yang dirumuskan dasarnya oleh al-Habīb 'Abd Allāh b. 'Alawī al-Haddād dapat merujuk, Fikri Mahzumi, "Prinsip dan Ajaran Tasawuf "Abd Allāh al-Haddād", Teosofi: Jurnal Tasawnf dan Pemikiran Islam, Vol. 2, No. 1 (2012), 1-8. Sementara dalam praktik tarekatnya dapat merujuk, Fikri Mahzumi, "Telaah Sosio-Antropologis Praktik Tarekat 'Alawìyah di Gresik", Maräjï' Jurnal Studi Keislaman, Vol. 1, No. 1 (2014), 5780. 
turun-temurun sampai kepada para guru sambung menyambung. ${ }^{19}$ Sedangkan J. Spencer Trimingham mendefinisikan, tarekat adalah suatu metode praktis untuk menuntun atau membimbing seseorang murid secara berencana dengan jalan pikiran, perasaan, dan tindakan terkendali secara terus menerus kepada suatu rangkaian dari tingkatantingkatan (maqāmāt) untuk dapat merasakan hakikat yang sebenarnya. ${ }^{20}$

Dari beberapa definisi yang dikutip di atas, meskipun berbeda dalam bahasa yang digunakan dalam mendefinisikan istilah tarekat namun substansi penjelasannya sama yaitu tarekat adalah hasil pengalaman seorang sufi yang diikuti oleh para murid menurut aturan tertentu seperti zikir, riyadah, doa, ibadah sunah yang bertujuan mendekatkan diri kepada Allah. Pengalaman spiritual para sufi ini bersifat individual karena kemungkinan pengalaman antarsufi berbeda satu dengan yang lain. Meskipun praktik antartarekat berbeda namun tujuannya sama yaitu menuju pada ma'rifat Allah. Di antara ritual tarekat yang umum dilakukan oleh seorang murid adalah zikir. Beberapa tarekat yang sangat mementingkan muridnya fokus pada zikir, karena zikir merupakan wirid yang tidak bisa diabaikan bagi mereka yang menjalani laku sulük menuju ma'rifat Allah.

Lafal zikir secara etimologi berasal dari kata dhakara-yadhkuru-dhiker yang berarti mengingat, menyebut, dan mengucapkan. ${ }^{21}$ Adapun pengertian istilah zikir merupakan ucapan lisan, gerakan raga, maupun getaran hati sesuai ajaran agama dalam rangka mendekatkan diri kepada Allah. Menurut Ibn 'Atā' Allah al-Sakandarī, zikir adalah proses pembersihan diri dari lalai dan lupa, dengan selalu menghadirkan al-Haqq dalam kesehariannya, secara berulang-ulang menyebut nama Allah dengan hati dan lisan, atau menyebut salah satu sifat dari sifat-sifat-Nya demi mendekatkan diri kepada-Nya. ${ }^{22}$

Teknik pelaksanaan zikir itu bervariasi sesuai dengan aliran tarekat. Begitu juga lafal zikir, ada yang terikat (muqayyad) pada waktu dan tempat tertentu, ada yang kondisional (mu'allaq). Masih menurut Ibn 'Ața' Allah, zikir dapat dibedakan menjadi tiga macam: 1) Zikir lisan atau sering disebut dhikr jahr, yaitu zikir yang diucapkan dengan

19 Aboebakar Atjeh, Pengantar Ilmu Tarekat: Uraian-uraian tentang Mistik (Solo: Ramadhan, 1990), 67.

20 Trimingham, The Sufi Orders, 3-4.

21 Ahmad Warson Munawir, Kamus Arab Indonesia (Jakarta: Pustaka Progressif, t.th.), 235.

22 Ibn 'Atā' Allah al-Sakandarī, Miftāḥ al-Falāḥ wa al-Miṣāạ al-Arwāḥ (Mesir: Maktabah al-Mustafā al-Bāb al-Ḥalabī, 1381 H), 4. 
lisan dan terdengar dengan jelas apa yang diucapkan seperti membaca kalimat tauhid dan tahmid; 2) Zikri kalbu, yaitu zikir yang digerakkan oleh hati, tanpa lisan dan tanpa suara. Jenis kedua ini umum disebut dhiker sirr, 3) Zikir hakiki, yaitu zikir yang melibatkan seluruh jiwa dan raga dan disatukan segenap ekspresi manusia sehingga seluruhnya terpusat hanya kepada Allah semata. ${ }^{23}$

Dalam melaksanakan zikir proses awal dhikr Allah dimulai dengan tafakkur atau kontemplasi dengan memusatkan pada tiga hal: 1) Allah adalah Zat yang Maha Kuasa dan Maha Pengatur segala ciptaanNya; 2) Manusia diciptakan hanya untuk mengabdi kepada-Nya; 3) Allah adalah Zat yang Maha Pengasih dan Penyayang. Kontemplasi dengan mengingat tiga hal ini akan memperkuat optimisme dalam upaya pencapaian tujuan. Sementara makna zikir menurut TNK adalah aktivitas lisan maupun batin/hati untuk selalu menyebut dan mengingat Asmä' Allah, baik berupa kalimat maupun ism al-Dhät (nama Allah). Lafal dan penyebutan zikir tersebut harus disertai dengan baiat atau talqin oleh murshid kepada murid.

Pada dasarnya TNK mengajarkan dua jenis zikir, yaitu: 1) Zikir nafy ithbät, dan 2) Zikir ism al-Dhät. Adapun yang dimaksud dengan zikir nafy ithbät ialah zikir dengan menyebut kalimat tahlil, là iläh illa Allah. Zikir ini merupakan substansi ajaran TNK yang dilakukan secara jahr (bersuara atau diucapkan dengan lisan dan diiringi gerak geleng-geleng). Sedangkan zikir ism al-Dhät dilakukan dengan menyebut ism Allah, Allah, Allah, zikir jenis kedua ini biasa dibaca secara samar (sirr atau khafi). Kedua jenis zikir inilah yang menjadi karakteristik dari ajaran TNK yang diterimakan kepada setiap murid saat baiat pertama. Di kalangan TNK ritual zikir bagi pelaku tarekat (sälik) memiliki makna filosofis tentang kejadian manusia, pembersihan jiwa, dan tarbiyah. Baik zikir nafy ithbät maupun ism dhät yang masing-masing dilakukan secara jahr dan khafi disertai gerakan yang disesuaikan dengan tempat-tempat latifah-latifah yang ada.

Posisi zikir dalam tarekat sangat urgen mengingat manusia dengan keterbatasan dan kelemahan yang dimiliki mendorong dirinya untuk mencari sesuatu yang magis. Dalam hal ini umat Islam memiliki dunia tasawuf sebagai jalan mediasi yang menghubungkan manusia dengan Tuhan dalam rangka memohon pertolongan dariNya. Di sisi lain manusia sebagai makhluk sosial menpunyai dua unsur yaitu, jasmani

23 H.A. Rivay Siregar, Tasawnf dan Sufisme Klasike ke Neo Sufisme (Jakarta: Raja Grafindo Persada, 2002), 246. 
atau rohani. ${ }^{24}$ Keduanya tidak terlepas dari kebutuhan hidup; jasmani berasal dari tanah, sementara roh manusia berasal dari Allah maka kebutuhan juga harus berasal dari Allah yakni agama. Bahkan kebutuhan lahir tidak dapat terpuaskan tanpa melibatkan peran agama. Peran agama yang dimaksud di sini adalah jalan yang menghubungkan seorang hamba dengan Pencipta-nya dalam bahasa tasawuf disebut tarekat, kontemplasi dalam tarekat dikenal dengan zikir.

Mencari ketenangan batin di tengah dominasi nilai-nilai materialisme dan hedonisme budaya di kehidupan modern. Pencarian ketenangan batin, tidak didapatkan dalam berbagai majelis pengajian yang lebih menekankan ajaran eksoteris (figh). Di luar tujuan ini, adanya motif-motif lain dari tiap individu jemaah, tapi dalam perspektif sufisme, motif maupun tujuan yang paling esensial adalah mencari Allah dan Rasulullah. Motif dan tujuan terakhir ini yang melahirkan sistem transmisi keilmuan dalam tradisi sufisme berbeda dengan transmisi keilmuan dalam pendidikan ilmu lainnya.

Dalam perspektif tarekat bahwa melakasanakan ibadah secara intensif menjadi titik sentral amaliah setiap waktu dengan mempertautkan diri kepada Allah melalui zikir, baik secara lisan ataupun batin. Orang yang telah melaksanakan ibadah zikir secara intensif, bagi penganut tarekat tidak secara otomatis menjadi jaminan bahwa orang tersebut akan sampai pada tujuan hakiki dari ibadah, yakni terjalinnya hubungan yang intens dengan Allah sebagai sumber kebenaran. ${ }^{25}$ Para pendaki alam spiritual selalu berusaha mempertahankan kekuatan batin dengan berlandaskan kepada alQur'ān dan sunnah demi mencapai pencerahan dan kebersihan jiwa. ${ }^{26}$ Dengan demikian jiwa yang bersih hanya bisa dicapai melalui ibadah yang intensif dan kontinu yang tidak mengenal batasan waktu dan tempat. Para penganut tarekat, mata hati harus menjalin komunikasi dengan Allah walaupun pada saat yang bersamaan sedang melakukan aktivitas dunia.

Salah satu ajaran tarekat yang diyakini penganutnya bahwa jiwa yang bersih dan bening akan cepat dan peka menangkap sinyal-sinyal

24 Abdul Muhaya, Peranan Tasawuf dalam Menanggulangi Krisis Spiritual (Yogyakarta: Pustaka Pelajar, 2001), 19.

25 Ibid.

${ }^{26}$ Mukhammad Zamzami, "Nilai Sufistik Pembudayaan Musik Shalawat Emprak Pesantren Kaliopak Yogyakarta”, Marâji : Jurnal Studi Keislaman, Vol. 2, No. 1 (2015), 44-66. 
spiritual yang dipantulkan Allah kepada siapa yang dikehendaki-Nya. Dari keyakinan ini, secara prinsipil pengamalan zikir bagi penganut tarekat bertujuan untuk meraih kesucian jiwa yang sedalam-dalamnya, sebab jiwa yang bersih akan mudah terpantul semua kebaikan termasuk mengenal, mendekati, dan bermakrifat kepada Allah. Bahkan akan mampu mencapai tingkat kashf (ketersibakan kebenaran hakiki) yang tidak dapat dibahasakan dalam bentuk verbalistik atau diungkapkan pada orang lain. Kekuatan jiwa yang telah mencapai tingkat kashf ini akan selalu terpaut dengan Allah dan tidak mudah terpengaruh oleh unsur-unsur duniawi dengan berbagai macam perhiasannya yang relatif dan semu.

\section{Proses Ritual Zikir Tarekat Naqshabandīyah Khālidīyah MPTTI}

Perkembangan kehidupan tarekat dewasa ini mewarnai masyarakat di kota-kota besar. Demikian pula dalam diskusi dan seminar pada tingkat akademisi tarekat menjadi tema yang terus menarik untuk diperbincangkan. Hal ini cukup beralasan sebab tarekat atau tasawuf secara umum mementingkan aspek batin yang memang menjadi kebutuhan masyarakat kota yang dekat dengan materialisme, demi meraih ketenangan batin, membuktikan identitasnya sebagai Muslim yang taat, merengkuh pengalaman spiritual, dan menghindari frustrasi sebab kehampaan hidup yang materialistik.

Untuk menelusuri peran tarekat dalam pembinaan mental spiritual pada dinamika sejarah kehidupan umat Muslim patut dihargai pendapat John Obert Voll dan H.A.R Gibb. Mereka berdua berpandangan ada tiga komunitas yang selalu terlibat dalam proses kontinuitas dan perubahan peradaban Islam, yakni ulama fikih, para pedagang Muslim (organisasi komersil), dan asosiasi sufi (tarekat). Yang disebut terakhir ini menurut John Obert Voll, awalnya merupakan kumpulan dari sekelompok murid yang hidup bersama dan menjalankan ajaran-ajaran sufi yang terkenal. Sejak abad ke-12, organisasi ini semakin resmi, dan tarekat semakin berskala lebih luas menjadi asosiasi yang berdasarkan kesalehan. Mereka melakukan fungsi-fungsi yang ruang lingkupnya lebih luas, yang dapat meningkatkan integrasi dan kohesi (kesatuan sosial keagamaan). ${ }^{27}$

27 John Obert Voll, Islam: Continuity and Change in the Modern World (New York: Publishing Press, 1997), 130. 
Dalam kaitan ini al-Qushāshī menyatakan bahwa sufi yang sebenarnya bukan orang-orang yang wұlah (memalingkan diri dari masyarakat), tetapi mereka yang tetap aktif dan kreatif di tengah kehidupan masyarakat serta melakukan al-amr bi al-ma'rüf wa al-naby 'an al-munkar demi kemajuan dan kesejahteraan masyarakat. ${ }^{28}$ Konsep tasawuf sebagaimana yang diuraikan al-Qushāsh $\overline{1}$ inilah yang dikembangkan oleh TNK MPT'TI di Gorontalo, yang menjunjung tinggi peran akal dan membuka diri terhadap pemikiran baru, mendorong intraksi praksis maupun teoretis terhadap fenomena sosial masyarakat yang selalu dinamis. Namun demikian, di saat yang sama hati selalu tetap terjaga tulus ikhlas dalam menapaki jalan hidup, dan tetap menjadikan iman sebagai ruh penggerak etos bermasyarakat yang penuh cinta dan kebaikan.

Dalam konteks ini Azyumardi Azra menjelaskan bahwa ada dua model utama sufisme yaitu: pertama, sufisme kontemporer, semua lapisan masyarakat bisa mengikutinya, model kelompok ini aktivitasnya tidak berdasarkan pada sistem kesufian klasik, pengajiannya sangat terbuka (dialog kritis dengan argumentasi logis) tempatnya kadang di hotel berbintang, narasumber dari cendekiawan kampus ternama. Model ini berkembang di kampus-kampus perguruan tinggi umum; dan kedua, sufisme konvensional, gaya sufisme yang karib dengan masyarakat. Jenis sufisme kedua ini kini juga sangat diminati dalam bentuk tareakat seperti tarekat Qādirīyah, Naqshabandīyah, Shādhilīyah, dan lainnya.

TNK MPTTI sendiri dari segi mazhab fikih mengikuti hukum fikih mazhab Shāficiyah, dari segi akidah mengikuti mazhab kalam al'Ash'ārīyah (Abl al-Sunnah wa al-Jamā'ab). Dalam menjalani sulük menuju ma'rifat Allab TNK MPTTI mewajibkan setiap murid agar di bawah bimbingan dan pengawasan murshid yang sudah sampai pada sifat Kämil Mukammil (guru yang sempurna dan menyempurnakan, yang dapat membimbing agar murid tidak salah jalan). Dasar yang digunakan bahwa setiap murid yang ber-sulük harus dengan tuntunan seorang guru adalah sebuah hadīth yang berbunyi:

$$
\text { كن مع الله وان لم تكن مع الله فكن مع من مع الله فا نه يصيلك الي الله }
$$

Hendaklah engkau selalu bersama Allah, kalau tidak dapat selalu bersama dengan Allah, maka bersamalah orang yang selalu

\footnotetext{
28 Aḥmad al-Qushāshī, al-Simt al-Majīd (Haedrabat: Dā’irāt al-Ma‘ārif al-Niẓāmīyah, t.th), 199-120.
} 
bersama dengan Allah, sesungguhnya ia akan mengantarmu sampai kamu kepada Allah.

Hubungan syariat dan hakikat adalah menyatu dan sama sekali tidak bisa terpisahkan, dengan demikian penghayatan dan pengamalan keagamaan eksoteris (ibadah ritual) dan esoteris (olah spiritual) harus berjalan seimbang. Penekanan pada salah satu aspek akan menghasilkan ketimpangan dan menyalahi prinsip ekuilibrium (tawā̌un). Dengan prinsip keseimbangan dan keteguhan jiwa dalam ketaatan syariat dalam pembersihan jiwa dari hawa nafsu dan menjadikan al-Qur'ān dan hadīth sebagai tolak ukur menjadikan TNK berada pada kedudukan tarekat muktabarah yang banyak diikuti masyarakat luas. ${ }^{29}$

Dari penjelasan di atas, dapat dipahami bahwa TNK MPTTI yang dikembangkan di Kota Gorontalo bercirikan tasawuf yang mengintegrasikan antara syariat dan hakikat, syariat yang dimaksud di sini adalah segala yang berhubungan dengan aspek lahiriyah manusia. Sedangkan hakikat berkenaan dengan aktivitas batin. Hal ini bermakna sebelum memasuki pintu tarekat dan hakikat seorang murid haruslah menyiapkan landasan syariat yang kuat. Dalam hal ini TNK lebih dekat dengan ajaran tasawuf Imam al-Ghazali ${ }^{30}$ dan mempunyai kemiripan dengan konsep tasawuf modern yang dikembangkan Buya Hamka.

Sebagaimana tarekat lain, TKN mendasari ajaran tasawufnya pada konsep ibssān yaitu "menyembah Allah seolah melihatNya, atau menyembah Allah seolah Allah selalu melihatnyā." Yang dimasud "melihat" adalah menyaksikan dengan mata hati dan mata ruh, yakni dengan dhuq wujdàn pada maqām fanä. Kalau belum sampai pada tingkatan ini, maka hendaklah seorang murid selalu merasa diawasai

${ }^{29}$ Alwi Shihab, Antara Tasawnf Sunni dann Tasawnf Falsafi: Akar Tasawnf di Indonesia, terj. Muhammad Nursamad (Depok: Pustaka IIMaN, 2009), 188. Abuya Shaykh H. Amran Waly al-Khalidi (Pimpinan Majelis Pengkajian Tauhid Tasawuf Indonesia dan Shaykh Tarekat Naqshabandīyah Khālidīyah), Penjelasan Ajaran Taubid Tasawuf, makalah disampaikan pada Muzakarah Pengkaderan Tauhid Tasawuf Asia Tenggara Pertama di Provinsi Gorontalo pada tanggal 14-16 November 2017 M.

30 Konsep penyucian mental spiritual dalam Majelis Pengkajian Tauhid Tasawuf Indonesia pada dasarnya mengarah kepada konsep tasawuf Imam al-Ghazālī, yang dimulai dari 1) Takhalli, yakni membersihkan jiwa dari akhlak tercelah (akblàq madhmümab), setelah bersih dari sifat tercelah maka diisi dengan 2) Tahalli, yakni mengisi jiwa dengan akhlak terpuji (akbläq mahmüdah, dan tahap selnjunya adalah 3) Tajallī, yakni tersingkaplah hijab antara hamba dan al-Khāliq. Abū Ḥāmid al-Ghazālī, Ibyà Ulūm al-Dìn, Vol. 4 (Kairo: Dār al-Taqwā li al-Turāth, 2000), 143. 
Allah dalam setiap gerak anggota tubuh dan apa yang terbesit dalam hati. Penerapan konsepsi ihsan ini tidak lain demi menyempurnakan ibadah. ${ }^{31}$ Sebagaimana disinggung sebelumnya, tujuan hakiki dari tarekat tidak lain adalah mengetahui yang Maha Benar (ma'rifat alHaqq). Makrifat sendiri adalah pancaran hati dan ruh yang suci. Pada kondisi ini Allah memperkenalkan diri-Nya kepada hati hamba yang Ia kehendaki, sehingga hamba tersebut senantiasa memandang wujudNya pada setiap denyut jantung, kapan dan di mana pun ia berada "Allah selalu dalam hatinya". ${ }^{32}$

Literatur resmi TNK MPT'TI membagi tauhid pada tiga bagian:

1. Tauhid akidah yaitu meyakini adanya Allah, sifat-Nya, mentaati perintah dan menjauhi larangan-Nya. Dialah yang wajib disembah, serta melihat kekuasaan Allah melalui pedekatan rasional.

2. Tauhid tasawuf yaitu meyakini adanya Allah dengan pendekatan budūr Allah fì qalbih (hatinya terpaut dengan Allah) melalui dhuq wujdān pada maqām fanä.

3. Tauhid sufi yaitu puncak ma'rifat Allah dalam kondisi wahdat alwujūd yang diperoleh melalui dhauq wujdan sehingga sampai pada tingkat makrifat (mengenal Allah dengan Allah, setelah fanàa' al-'ärif ma'a al-ma'rüf). ${ }^{33}$

Sebagai suatu mazhab dalam tasawuf, TNK adi MPT'TI memiliki ajaran yang mencirikan dirinya dari tarekat lain khususnya dalam halhal kesufian. Beberapa ajaran yang merupakan pandangan para komunitas tarekat ini bertalian dengan masalah tarekat atau metode untuk mendekatkan diri kepada Allah. Metode tersebut diyakini sangat efektif dan efisien, hal ini dilatarbelakangi oleh ajaran tarekat ini berlandaskan kitab suci al-Qur'ān dan hadīth serta sulük yang diterima dari ulama al-salaf al-săliḥ. Tujuan perjalanan tarekat ini pada intinya merealisasikan tiga pendakian spiritual yaitu: pertama, kesempurnaan sulük; kedua, adab (etika) zikir kepada Allah; dan ketiga, murāqabah (mendekatkan diri) kepada Allah.

Shaykh Abdul Khaliq Ghujdawany mengajarkan 11 langkah ajaran dasar untuk memasuki pintu tarekat, delapan langkah berasal dari Shaykh 'Abd al-Khāliq Ghujdawany, dan tiga langkah berasal dari Muhammad Bahā' al-Dīn al-Uwaysī. Adapun delapan langkah yang dimaksud adalah:

\footnotetext{
31 al-Khalidi, Penjelasan Ajaran, 4.

${ }^{32}$ Lihat selengkapnya, Ibid., 4.

${ }^{33}$ Ibid., 11-15.
} 
1. Hosh Dar Dam, yaitu seorang sufi haruslah sadar setiap menarik nafas, menghembuskan nafas dan ketika berhenti sebentar di antara keduanya. Perhatikan pada nafas dalam keadaan sadar bahwa Allah memberikan kekuatan spiritual dan membawa seorang sufi lebih dekat kepada Allah;

2. Nadhar Bar Qadam, yaitu seorang murid haruslah menjaga langkah sewaktu berjalan dan memandang ke depan sewaktu duduk agar tujuan rohaninya tidak diganggu oleh sesuatu yang tidak relevan;

3. Safar Dar Wathan, yaitu melakukan perjalanan batin dengan meninggalkan segala bentuk yang tidak sempurna menuju kesadaran dirinya sebagai mahluk yang sempurna;

4. Khalwat Dar Anjuman, yaitu Allah senantiasa hadir dalam hatinya walaupun ia berada pada alam keramaian;

5. Yad Kard, yaitu terus menerus berzikir kepada Allah dengan zikir lisan dan batin, supaya nama Allah terpatri di dalam hatinya;

6. Bą Gasht, yaitu mengucapkan ilähì Anta Maqsüdì, wa rid̄àk matlübì (Ya Allah Engkaulah tempatku bermohon dan keridhaanMu lah yang kuharapan). Kalimat ini dibaca dengan tujuan mengendalikan hati dan terjaga ingatan hanya kepada Allah semata;

7. Nigah Dasyat, yaitu menjaga hati, perasaan, dan pikiran ketika melakukan zikir tauhid;

8. Yad Dasyat, yaitu menangkap secara langsung zat Allah melalui penglihatan yang diberkahi. Tingkatan ini hanya dapat dicapai oleh rohani tertinggi.

Sedangkan tiga langkah yang diajarkan Muhammad Bahā' al-Dīn al-Uwaysī adalah:

1. Wuqüf Zamānì, yaitu introspeksi diri atau mengamati secara teratur bagaimana seseorang menghabiskan waktunya. Jika waktunya dihabiskan untuk berzikir kepada Allah, itu adalah pertanda hatinya sudah terjaga;

2. Wuqüf 'Adadì, yaitu berzikir dengan hati yang terpaut dengan Allah (menjaga hati ketika berzikir);

3. Wuqüf Qalbi, yaitu berzikir dengan ingatan yang hanya fokus kepada Allah (hati tidak mengembara kemana-mana). ${ }^{34}$

Inilah beberapa ajaran dasar TNK MPT'TI ketika seorang hamba ingin melaksanakan sulük untuk mendapatkan maqām ḥaqiqag dan ma'rifat Allah. Setelah langkah berzikir sudah dilakukan dengan

\footnotetext{
${ }^{34}$ Syekh H. Amran Waly al-Khalidi, Sahịfat al-Safä (Banda Aceh Barat: Sinar Indah Meulaboh, t.th.), 3-4.
} 
sempurna, maka langkah selanjutnya adalah zikir ism Dhät yang berarti zikir memperbaiki hati (sahifat al-Safä/lembaran yang bersih). Untuk mengamalkan zikir ism Dhät ini diharuskan mengamalkan tiga hal, yakni:

1. Räbitat al-Sharifah, yaitu menghayalkan atau membayangkan wajah shaykh murshid di antara dua kening yang bercahaya sampai ke lubuk hati yang dalam, yakin perbuatan, sifat dan zatnya. Dalam konsep tasawuf Naqshabandiyah shaykh inilah yang selalu membimbing untuk mengingat Allah.

2. Wuqüf al-Qalbì, yaitu menghadirkan Allah dalam hati dengan jalan menyatukan kemauan yang ada dalam pikiran, panca indera serta hati sanubari yang bening. Menyerahkan sepenuhnya hati kepada Allah, dan hati dijaga agar terpatri terus dengan Zat Yang Maha Agung.

3. Dawām al-Dhikr, yaitu mengekalkan zikir, langkah-langkahnya adalah:

a. Diyakini bahwa jasmani bersih dari hadas besar dan hadas kecil, dan rohani bersih dari dosa;

b. Salat Hajat dua rakaat dan bermunajat kepada Allah agar dibukakan pintu kemudahan untuk mencapai ma'rifat Allah;

c. Meletakkan tangan di atas paha dan mata dipejamkan (agar lebih khusyuk);

d. Membayangkan semua dosa yang pernah diperbuat dan menyesalinya sambal membaca:

$$
\text { استغفر الله العظيم الذي لا اله الا هو الحي القيوم و اتوب اليه }
$$

e. Membaca surah al-Fātiḥah satu kali dan surah al-Ikhlāṣ tiga kali dengan niat pahalanya diahdiahkan kepada Rasulullah dan imam tarekat Shaykh Bahā' al-Dīn Naqshabandī sambil bermunajat, Hai rub shaykh Naqshabandi tolong dan bantulah aku diberi kemudahan dalam bermakrifat kepada Allah;

f. Memejamkan kedua mata, menutup mulut, dan menongkatkan lidah ke langit-langit;

g. Setelah itu membayangkan diri sudah menghembuskan nafas terkhir dan dalam proses menuju alam kubur untuk mempertanggungjawabkan semua amal perbuatan di dunia;

h. Rabitah Shaykh, yaitu membayangkan wajah shaykh penuh kasih sayang di antara dua kening bercahaya sampai ke lubuk hati yang bening (perbuatan, sifat, dan zatnya) sehingga fanalah wujud kita ke dalam wujudnya, dan jadilah berhadapan dengan Allah, lalu 
bermunajahat, Ya Allah dengan berkat guru ini, bukakanlah pintu makrifat untukk.u, sebab shaykh inilah yang dapat memberikan bimbingan sampai kepadaMu.

i. Wuqüf Qalbì (hati melihat tulisan kalimat Allah), sambil mengingat makna ayat:

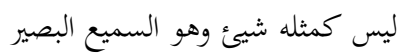

j. Membaca doa penutup:

بسم الله الر حمن الرحيم .اللهم اني اسئلك التوبة والانابة والاستقامة علي الشريعة الغراء والطريقة البيضاء

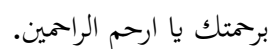

Ya Allah aku memohon ampunan kepada-Mu. Berikan kepada kami inäbah, istikamah dalam menjalani syariat-Mu dan tarekat yang muktabarah, wahai Zat Yang Maha Pengasih dan Penyayang. ${ }^{35}$

Inilah langkah-langkah dan prosesi yang dilakukan pengikut TNK MPPT-I ketika bersulük menuju ma'rifat Allah. Kegiatan ini wajib dilakukan setiap hari baik secara berkelompok maupun secara pribadi, sampai seorang hamba mencapai puncak pendakian spiritual yakni ma'rifat Allah.

\section{Zikir Bagi Jemaah Tarekat Naqshabandīyah Khālidīyah MPT'TI}

Pada bagian terakhir artikel ini peneliti lebih fokus memaparkan pola pikir (mindset) masyarakat Kota Gorontalo yang aktif sebagai komunitas TNK MPT'TI dalam memahami dan memaknai ritual zikir yang meraka lakukan. TNK MPTTI menyakini bahwa zikir merupakan pokok dari rangkaian sulük yang dijalani setiap murid tarekat agar bisa menggapai puncak pengalaman spiritual yaitu ma'rifat Allah. Tidak hanya itu, bagi pelaku sulük zikir pun diyakini memiliki relevansi dengan aktivitas keseharian seorang murid karena berimplikasi pada kondisi batin sehingga murid tersebut dengan mudah mengatasi persoalan-persoalan yang dihadapi dalam kehidupannya.

Secara spesifik jawaban dari Jemaah TNK MPPT-I secara umum mengatakan bahwa zikir adalah mengingat Allah secara lisan dan kadang secara samar dengan gerakan hati kapan pun dimana berada. Zikir paling tidak memberi sugesti, motivasi, dan kekuatan bagi pengamal zikir dalam mengarungi kehidupan. Fungsi zikir menurut sebagian besar Jemaah TNK MPPT-I dapat memberi pencerahan bagi

${ }^{35}$ Ibid. 
mereka untuk mengatasi pelbagai problem kehidupan apabila pengamal tersebut secara istikamah berzikir setiap waktu. Sebab ketika berzikir mereka sedang mengingat Allah, maka tumbuh di dalam hatinya keyakinan bahwa setiap yang terjadi di kehidupan dunia tidak lepas dari kekuasaan Allah, sehingga setiap persoalan yang sedang mereka hadapi akan dipasrahkan kepada-Nya sebagai pemilik segala perkara. Selain itu para jemaah TNK MPPT-I meyakini, agar seorang pengamal tarekat (sälik) bisa sampai pada puncak pengalaman spiritual, maka seorang salik wajib melanggengkan zikir (mengingat Allah). Oleh karenanya di TNK MPPT-I posisi zikir bagi tarekat ini sanagat penting. Seorang jemaah TNK MPPT-I, Dra. Hj. Hadijah Tahang menjelaskan,

"Dalam dunia tarekat, zikir bukan hanya sekadar teori, tetapi sebuah pola pikir yang diyakini sehingga memberikan efek positif bagi pengamalnya. Efek tersebut dapat dilihat ketika seseorang pengamal zikir mengalami perubahan psikologis seperti mudah mengontrol emosi dalam dirinya. Dengan sugesti zikir hati menjadi damai, tenteram, lapang, dan selalu berpikir positif. Lafal-lafal zikir yang dirapal dengan hati secara istikamah pasti memberikan sinyal positif yang bedampak pada pola pikir dan perilaku seseorang." 36

Setali dengan pandangan Hadijah, Abdul Manan Podungge meyakini,

"Allah memberikan kemuliaan, jabatan, kelebihan rejeki kepada hambaNya yang dikehendaki, selama hamba tersebut menjalin komunikasi yang intensif dengan khalikNya dengan cara selalu berzikir, ber-tawajjuh, dan melaksanakan ibadah-ibadah lain. Energi zikir yang terekam dalam jiwa yang bening akan membuka jalan menuju ma'rifat Allah. Secara tidak berlebihan kami mengungkapkan bahwa selama kami berkumpul dalam ikatan Tarekat Naqshabandīyah Khālidīyah MPTTI di Kota Gorontalo selalu merasa qanāab terhadap limpahan rejeki yang berikan Allah. Dan ketika usaha kami diuji dengan kerugian hati kami juga tetap qanáah. Kami meyakini apa yang kami rasakan ini karena energi spiriitual karena telah membiasakan diri utuk selalu berzikir". ${ }^{37}$

Dari keterangan beberapa sumber yang dikutip sebelumnya, dapat diambil simpulan bahwa melalui zikir yang rutin dan istikamah diamalkan, para anggota jemaah TNK MPTTI di Gorontalo merasa kehidupan mereka jauh lebih tenteram, jiwa mereka menjadi tanang, dan pikiran mereka pun semakin jernih. Dalam kondisi ini mereka

${ }^{36}$ Dra. Hj. Hadijah Tahang, Wawancara, Gorontalo 14 Juli 2018.

37 Abdul Mannan Podungge, Wawancara, Gorontalo 1 Agustus 2018. 
lebih siap menghadapi problem-problem kehidupan karena optimis Allah akan selalu bersama dan menolong mereka. Mental atau rohani yang kondusif dalam diri jemaah TNK MPTTI ini mereka yakini karena faktor zikir yang mereka amalkan. Kedamaian jiwa dan pikiran yang jernih karena meyakini bahwa segala perkara itu berasal dari Allah membuat mereka siap secara mental menyongsong kehidupan yang memang tidak terus berjalan datar. Dalam susana batin seperti ini kedekatan dan kebersamaan dengan Allah semakin terasa sehingga merasa diri mereka sangat kedekatan dengan Allah.

Untuk membudayakan dhikr Allah di kalangan jemaahnya, TNK MPT'TI memberi pedoman agar setiap anggota jemaah memulai dengan berkontemplasi (tafakkur) pada tiga hal yakni: 1) Allah adalah Zat yang Maha Kuasa, Maha Dahsyat, dan Pengatur segala ciptaanNya; 2) Manusia diciptakan hanyalah untuk menyembah kepada Allah semata; 3) Allah adalah Tuhan yang Maha Pengasih dan Maha Penyayang. Kontemplasi dengan menghayati dan meresapi ketiga hal ini, diharapkan akan melahirkan rasa optimisme dalam diri setiap murid untuk mencapai tujuan tertinggi dari alasan mereka bertarekat yaitu ma'rifat Allah. Tengku Ismail menambahkan, dalam rangka menjadikan zikir sebagai kebutuhan hidup dan upaya untuk mengabadikan al-nafs al-mutma'innah dalam diri seorang murid, maka diperlukan sikap disiplin dan istikamah dalam empat hal: 1) $M u$ 'ähadah, yakni selalu ingat dan sadar akan janji yang telah diikrarkan antara hamba dan Pencipta (Allah); 2) Mubäsabah, yakni menganalisis dan memperhitungkan apa yang sudah dan akan dilakukan; 3) Muräqabah, yakni kesadaran rohani merasa bersama dan dekat dengan Allah; 4) Mujähadah, yakni kemampuan untuk menggerakkan semua potensi untuk menundukkan hawa nafsu. ${ }^{38}$

Hidup dalam suasana kejiwaan yang harmonis berdampak pada pembebasan diri dari ketergantungan struktural dan kultural. Pada gilirannya, pribadi yang memiliki ketenangan jiwa mampu mengukuhkan otonomi pribadinya di tengah kagalauan dalam menghadapi problem kehidupan. Oleh karenanya menurut hemat penulis, zikir bisa menjadi the power of spiritual revolution yang mampu membangun pribadi kritis, kreatif, sikap optimis, dan bebas dari pragmatisme. Dari aspek psikologis, jemaah TNK MPTTI meyakini ada koherensi antara pengamalan zikir dengan penyelesaian problem

38 Tengku Ismail (Tokoh Tarekat Naqsyabandiyah al-Khalidi MPTTI), Wawancara, Gorontalo 16 Mei 2018. 
kehidupan yang mereka hadapi. Koherensi tersebut terletak pada terbangunnya sugesti dari dalam diri bahwa Allah selalu bersama dan akan menolong mereka mengatasi persolan hidup karena Allah lah pemilik segala perkara yang ada di dunia.

Fakta-fakta yang menguatkan bahwa zikir berdampak pada kehidupan jemaah TNK MPTTI, indikator itu ditemukan pada kemudahan anggota jemaah mendapatkan rejeki yang halal, rumah tangga yang harmonis, putra-putri yang baik, dan beberapa kondisi yang baik berdasarkan pengamatan langsung. Bahkan keyakinan akan efek positif dari pengamalan zikir itu menyentuh di ranah supranatural. Salah satu informan dengan jujur mengatakan, "berkat energi positif dari "air zikir" yang saya berikan kepada anak saya yang sudah lama menikah tapi belum dikaruniai buah hati (keturunan), dan energi positif zikir yang diamalkan (dengan niat tulus ikhlas), alhamdulillah anak saya sekarang sudah dikaruniahi momongan." ${ }^{40}$ Dengan keyakinannya yang sangat mendalam bahwa air yang sudah dibacakan zikir dan doa dapat mengandung berkah dan menyelesaikan masalah duniawinya, pengalaman ini memahamkan bahwa ada garis persinggungan antara domain spiritual yang sakaral dengan domain realitas yang profan. Dari hasil temuan ini dapat digarisbawahi bahwa wawasan jemaah TNK MPTTI terhadap makna zikir berada pada tingkat tauhid akidah. Mereka yang berada pada tingkat ini masih menyakini adanya hukum kausalitas dalam beribadah.

Selain tingkat tauhid akidah, ada tingkat yang lebih atas yaitu tauhid tasawuf. Mereka yang sudah berada pada tingkat ini, merasakan puncak ma'rifat Allah bahkan sampai pada pengalaman waḥdat al-wujūd melalui dhuq wujdān (mengenal Allah dengan Allah, setelah fanà' 'ärif dengan ma'rúf). Dalam kondisi demikian mereka yang berada pada tingkat tauhid sufi ini sudah melampau batas rasional. Zikir pada tingkat tauhid sufi ini menyatukan antara al-dhäkir wa al-madhzūir (pengingat dan yang diingat), hamba dan Tuhan pada situasi ini sudah bersatu dalam pengertian tidak ada yang ada kecuali Allah, segala sesuatu sudah fana kecuali $W$ ajh Allah. Mereka mendapat cahaya dari Allah, dan dengan cahaya itu memanggil dirinya untuk bersama Allah

\footnotetext{
${ }^{39}$ Mircea Eliade (1907-1986), sesuatu yang sakral dimengerti oleh manusia karena ia memanifestasikan dirinya memiliki perbedaan dari dunia profan. Manifestasi dari dunia sakral ini di sebut Eliade sebagai "hierofani", lihat Miecea Eliade, Sakral dan Profan, terj. Nurwanto (Yogyakarta: Fajar Pustaka Baru, 2002), 14-15.

${ }^{40}$ Dra. Hj. Hadijah Tahang, Wawancara, Gorontalo 14 Juli 2018.
} 
dalam zikir. ${ }^{41}$ Tengku Ismail menyatakan bahwa hakikat makna zikir yang paling tinggi itu ketika ingatan seorang hamba terpatri hanya kepada Sang Khäliq. ${ }^{42}$

Dalam praktiknya, ritual zikir pada TNK MPTTI di Kota Gorontalo lebih intensif di lakukan melalui kegiatan sulük ${ }^{43}$ yang dilaksanakan setiap bulan Ramadan dan Dzulhijah bertempat di Pondok Pesantren Darus Salam Banda Aceh. Hampir semua tarekat se-ASEAN yang berstatus muktabarah (dari berbagai aliran tarekat) berkumpul melakukan zikir secara berjamaah yang dipimpin langsung oleh Pimpinan TNK MPTTI (Abuya Shaykh H. Amran Waly alKhalidi). Kegiatan utama yang dilakukan dalam momen zikir bersama tersebut diawali dengan mandi taubat, salat taubat dua rakaat, dan membaca rangkaian tawasul, ${ }^{44}$ Yāsīn Faḍilah, Surah al-Wāqi'ah, kemudian dilanjutkan dengan prosesi tawäjuh kematian dan kubur (membayangkan diri kita sementara dikafani dan akan dibawa ke liang lahat kuburan yang gelap gulita). Ritual lain yang wajib dilaksanakan ketika sulük adalah mengganti ( $q a d \bar{a})$ semua salat fardu yang pernah ditinggalkan. ${ }^{45}$ Ketika melaksanakan sulük tidak dianjurkan bagi seorang salik membaca al-Qur'ān apalagi berniat mengkhatamkannya, hal ini dimaksudkan supaya peserta sulük mencapai keutuhan jumlah zikir yang sudah diniatkan.

\section{Catatan Akhir}

Zikir bagi penganut tarekat atau salik menempati posisi penting. Selain menjadi medium ibadah karena selalu menghadirkan Sang

\footnotetext{
${ }^{41}$ Hamdan Ladiku (Ketua Tarekat Naqsyabandiyah al-Khalidi MPTTI Gorontalo), Wawancara, Gorontalo 13 Juli 2018.

42 Tengku Ismail (Murshid pada Tarekat Naaqsyabandiyah MPT'TI Gorontalo), Wawancara, Gorontalo 25 Agustus 2018.

43 Sulük secara etimologis berarti jalan atau cara (kelakuan atau tingkah laku). Menurut al-Ghazālī sulük adalah proses penjernihan akhlak dan amal. Sulük dilakukan dengan sehingga amal lahir dan amal batin, semua kesibukan seorang salik (sebutan pelaku sulük) dicurahkan hanya kepada Allah, dengan terus berupaya membersihkan batinnya hingga siap wusül (sampai) kepada Allah.

44 Tawasul dengan membaca Surah al-Fātihah yang pertama ditujukan kepada Rasulullah Muhammad; tawasul kedua ditujukan kepada murshid tarekat; dan tawasul ketiga ditujukan kepada guru tarekat; serta yang keempat diniatkan untuk hajat masing-masing.

45 Dalam penjelasan Hamdan Ladiku kegunaan salat Qadā' adalah menggati salat yang pernah ditinggalkan segaja atau tidak sengaja sebagaimna sabda Nabi Muhammad man nasiya salätan falyusall idhä dhakarahā.
} 
Khalik di lisan dan hatinya, zikir pun melahirkan energi positif bagi pengamalnya sehingga terciptalah jiwa yang damai, pikiran yang jernih dan optimisme dalam diri pengamal yang secara istikamah dan ikhlas melanggengkan zikir di setiap aktivitasnya terutama pada waktu menjalani proses sulük. Sugesti yang lahir dari zikir itulah yang membuat pengamalnya mampu dan kuat menghadapi persoalanpersoalan yang muncul dalam kehidupannya. Tidak hanya itu, bagi pengamal tarekat, zikir pun bermuatan magis ketika pengalaman jemaah mendapati hal-hal supranatural yang tidak bisa diterima secara logis. Tujuan utama atau puncak dari pendakian melalui zikir tidak lain adalah ma'rifat Allah.

Tingkat pemaknaan terhadap zikir di kalangan jemaah TNK MPTTI sendiri memang beragam, namun berdasarkan temuan tahapan dari tingkat zikir sendiri terpilah menjadi: 1) Zikir tingkat tauhid akidah; dan 2) Zikir tingkat tauhid tasawuf. Pada tingkat pertama dimulai dengan menekankan beberapa poin yaitu: a) Allah adalah Zat yang Maha Kuasa, Maha Dahsyat, dan Pengatur segala ciptaanNya; b) Manusia diciptakan hanyalah untuk menyembah kepada Allah semata; c) Allah adalah Tuhan yang Maha Pengasih dan Maha Penyayang. Kondisi pengamal pada tingkat ini akan mereasa optimis dan memiliki ketenangan hati dan kemurnian jiwa sehingga mampu menghadapi persoalan-persoalan dalam hidupnya dengan tanpa kendala apalagi frustrasi. Pada tingkat kedua, zikir dimaknai sebagai tauhid tasawuf karena pada kondisi ini pengamal zikir sudah merasa ketergantungan dengan zikirnya. Sebab zikir memberi pengalaman wahdat al-wujüd yaitu perasaan menyatu antara hamba dan Tuhan. Inilah puncak pengalaman ma'rifat Allah.

\section{Daftar Rujukan}

al-Khalidi, Abuya Shaykh H. Amran Waly (Pimpinan Majelis Pengkajian Tauhid Tasawuf Indonesia dan Shaykh Tarekat Naqshabandīyah Khālidīyah). Penjelasan Ajaran Taubid Tasawuf, makalah disampaikan pada Muzakarah Pengkaderan Tauhid Tasawuf Asia Tenggara Pertama di Provinsi Gorontalo pada tanggal 14-16 November 2017 M.

al-Khalidi, Syekh H. Amran Waly. Sahifat al-Safä. Banda Aceh Barat: Sinar Indah Meulaboh, t.th.

Atjeh, Aboebakar. Pengantar Ilmu Tarekat: Uraian-uraian tentang Mistik.

Solo: Ramadhan, 1990. 
Azra, Azyumardi. Jaringan Ulama Timur Tengah dan Kepulauan Nusantara Abad XVII-XVIII. Jakarta: Kencana, 2010.

----. Renaisans Islam Asia Tenggara. Bandung: Rosda Karya, 2012.

Bruinessen, Martin van. Kitab Kuning, Pesantren, dan Tarekat, terj. Farid Wajidi. Yogyakarta: Gading Publishing, 2015.

-----. Tarekat Naqsyabandiyah di Indonesia: Survey Historis, Geografis, Sosiologis. Bandung: Mizan, 1996.

Eliade, Miecea. Sakral dan Profan, terj. Nurwanto. Yogyakarta: Fajar Pustaka Baru, 2002.

Fandī (al), Muhammad Sabit dkk. Dä’irāt al-Ma'ärif al-Islāmīyāh, Vol. 15. Teheran: Intisyarat Jahham, t.th.

Fata, Ahmad Khoirul. "Tarekat," al-Ulum, Vol. 11, No. 2, 2011.

Ghazālī (al), Abū Hạamid. Ibyà 'Ulūm al-Dìn, Vol. 4. Kairo: Dār alTaqwā li al-Turāth, 2000.

Ḥafnī (al), 'Abd al-Mun'im. al-Mawsū'ah al-Süfìyah. Kairo: Maktabah Madbūlī, 2003.

Hidayat, Komaruddin. Tragedi Rajan Midas: Moralitas Agama dan Krisis Modernisme. Jakarta: Paramadina, 1998.

Ismail, Tengku (Murshid pada Tarekat Naaqsyabandiyah MPTTI Gorontalo). Wawancara. Gorontalo 25 Agustus 2018.

----.. Wawancara. Gorontalo 16 Mei 2018.

Ladiku, Hamdan (Ketua Tarekat Naqsyabandiyah al-Khalidi MPT'TI Gorontalo). Wawancara. Gorontalo 13 Juli 2018.

Ma'luf, Lois. al-Munjid al-Lughāh wa A lām. Beirut: Dār al-Mashriq, 1975.

Madjid, Nurcholish. IslamKemodernan dan Keindonesiaan. Bandung: Mizan, 1999.

Mahzumi, Fikri. "Prinsip dan Ajaran Tasawuf 'Abd Allāh al-Haddād", Teosofi: Jurnal Tasawnf dan Pemikiran Islam, Vol. 2, No. 1, 2012.

----. "Telaah Sosio-Antropologis Praktik Tarekat 'Alawiyah di Gresik”, Marâji‘: Jurnal Studi Keislaman, Vol. 1, No. 1, 2014.

Muhaya, Abdul. Peranan Tasawuf dalam Menanggulangi Krisis Spiritual. Yogyakarta: Pustaka Pelajar, 2001.

Munawir, Ahmad Warson. Kamus Arab Indonesia. Jakarta: Pustaka Progressif, t.th.

Munir, Misbahul. "Rasionalisasi Gerakan Kewirausahaan Organisasi Tarekat Șiddîqîyah di Jombang”, Islamica: Jurnal Studi Keislaman, Vol. 9, No. 2, 2015. 
Nasr, Seyyed Hossein. Islam and The Plight of Modern Man. Bandung: Pustaka, 1991.

Nursi, Said. Sinar yang Mengungkap Sang Cabaya, terj. Hariyanto dkk. Jakarta: Murai Kencana, 2003.

Nursyam. Pembangkangan Kaum Tarekat. Surabaya: LEPKISS, 2004.

Podungge, Abdul Mannan. Wawancara. Gorontalo 1 Agustus 2018.

Qushāshī (al), Aḥmad. al-Simt al-Majìd. Haedrabat: Dā’irāt al-Ma‘ārif al-Niz̄āmìyah, t.th.

Rahman, Gazali. "Kontroversi Pemahaman dan Pengamalan Syariat Majelis Zikir Ya Allahu di Kota Gorontalo," al-Qalam, Vol. 23. No. 1, 2017.

Sakandarī (al), Ibn 'Atā' Allah. Miftāḥ al-Falāḥ wa al-Miṣbāḥ al-Arwāḥ. Mesir: Maktabah al-Mustafāa al-Bāb al-Halabī, $1381 \mathrm{H}$.

Shihab, Alwi. Akar Tasawuf di Indonesia. Depok: Pustaka IIMaN, 2009.

----. Antara Tasawnf Sunni dann Tasawnf Falsafi: Akar Tasawnf di Indonesia, terj. Muhammad Nursamad. Depok: Pustaka IIMaN, 2009.

Siregar, H.A. Rivay. Tasawnf dan Sufisme Klasik ke Neo Sufisme. Jakarta: Raja Grafindo Persada, 2002.

Tahang, Dra. Hj. Hadijah. Wawancara. Gorontalo 14 Juli 2018.

Trimingham, J. Spencer. The Sufi Orders in Islam. London: Oxford University Press, 1973.

Voll, John Obert. Islam: Continuity and Change in the Modern World. New York: Publishing Press, 1997.

Zamzami, Mukhammad. "Nilai Sufistik Pembudayaan Musik Shalawat Emprak Pesantren Kaliopak Yogyakarta", Marajii: Jurnal Studi Keislaman, Vol. 2, No. 1, 2015. 